\title{
MEASUREMENT OF LASER FUSION CAPSULES USING THE INTERFEROMETER METHOD OF EXCESS FRACTIONS
}

Roger R. Stone

April 7, 1975

Prepared for U.S. Energy Research \& Development Administration under contract No. W-7405-Eng-48

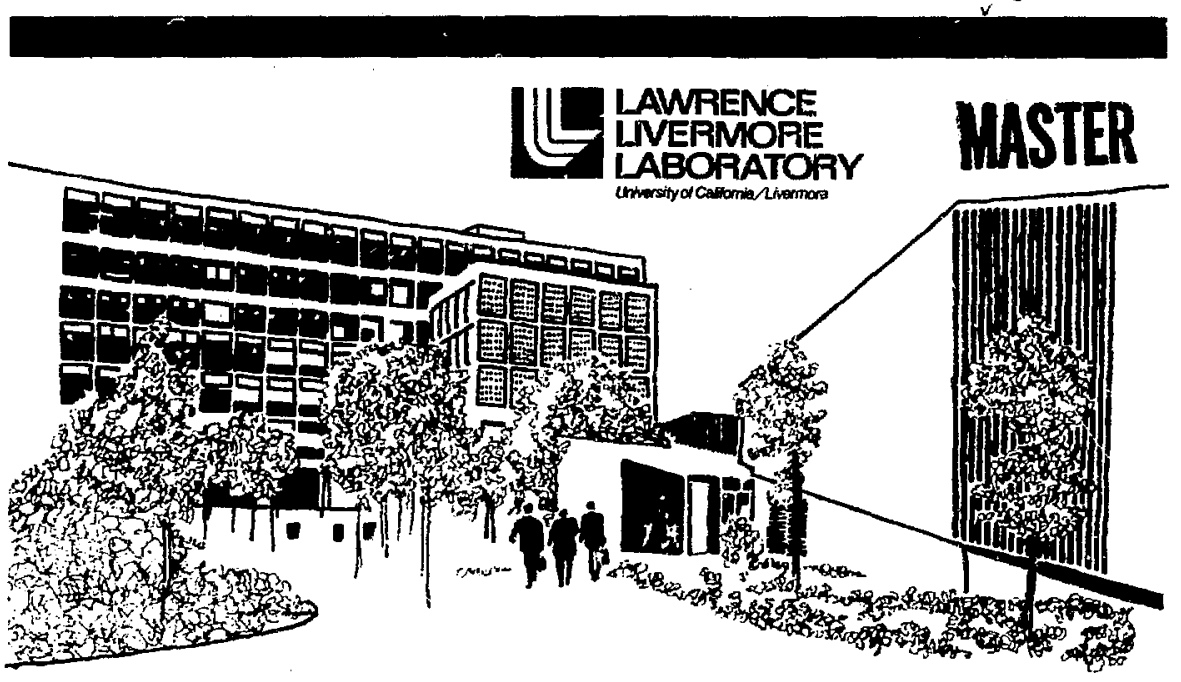


NOTICE

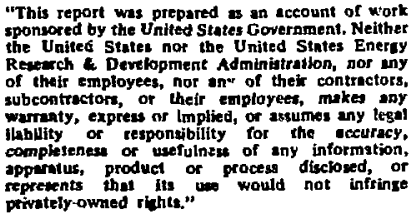

privately-awned riphts."

Printed in the United States of America Available from

National Technical Information Service

U.S. Department of Commerce

5285 Port Royal Road

Springfield, Virginia 22151

Price: Printed Copy \$_ * Microfiche $\$ 2.25$

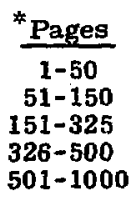

NTIS

Selling Price

$\$ 4.00$

$\$ 5.45$

$\$ 7.60$

$\$ 10,60$

$\$ 13.60$ 
TID-4500, UC-38

Engineering and Eguipment

\section{近 \\ LAWFENCE LNEFMORE LABOAATOFY \\ university of Callomia Livermore, Callomia 94550}

UCRL - 51788

\section{MEASUREMENT OF LASER FUSION CAPSULES USING THE INTERFEROMETER METHOD OF EXCESS FRACTIONS}

Roger R. Stone

MS. date: April 7, 1975

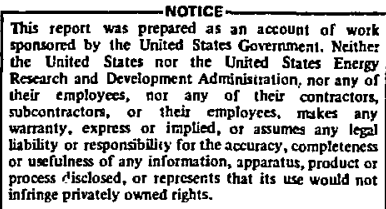

or usefulness of any informition, apparat us, product or
process disclosed, or represents that its use would not
infringe privately owned rights. 


\title{
MEASUREMENT OF LASER FUSION CAPSULES USING THE INTERFEROMETER METHOD OF EXCESS FRACTIONS
}

\begin{abstract}
A syctem is proposed to allow use of the method of excess fractions with a high-power interference microscope. This allows the measurement of average wall thicknesses for sma!l $(<200-\mu m$ o.d.,

and from $0.5-$ to $2.0-\mu \mathrm{m}$ wall thicknesses) transparent laser fusion targets to better than $0.5 \%$ and wall uniformity to better than $0.3 \%$. The DT gas fill of the capsules can be nondestructively measured to about $\pm 3 \%$.
\end{abstract}

\section{Introduction}

The basic laser fusion capsule used at the Law rence Livermore Laboratory and other labs is a small (<200- $\mu m-0, d$.$) ,$ transparent glass shell filled with equi-

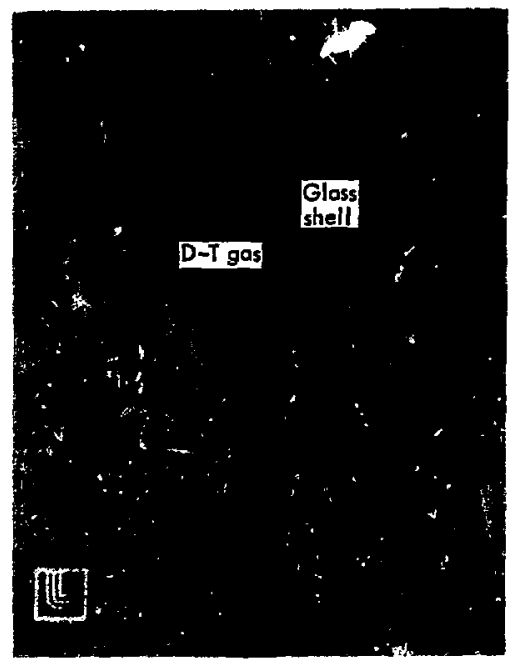

molar DT, Figure 1 shows such a target. The walls of the capsule are from about 0.5 to $2.0 \mu \mathrm{m}$ thick. Approximately two years ago, physics designers specified

Fig. 1. Trpical DT-filled transparent glass shell target for laser fusion. 
that it would be desirable to measure the wall thickness of the capsules to an accuracy of better than $1 \%$. As a result of work at LLL by $\mathrm{Gregg}^{1}$ and Stone, Gregg, and Souers, ${ }^{2}$ using the interference properties of light, an accuracy of the average wall thickness measurement of about $\pm 5 \%$ has been obtained.

Researchers at Los Alamos Scientific Laboratories (LASL) and at KMSF have utilized $x$-ray microradiography for wall thickness measurements with an accuracy of about $\pm 0.2 \mu \mathrm{m}$ for the shells of interest. $^{3-5}$

This report discusses a technique using the method of excess fractions and a high-quality interference microscope to measure the average wall thickness to better than $0.5 \%$. When further developed, this technique will plot average wall thickness of the shell to better than $0.5 \%$ and determine wall uniformity to better than $0.3 \%$. After considering the capabilities of this technique, the author feels that measurement of the wall oimensions of glass shells is no longer a theoretical problem but is now a practical problem of resources and determining whether or not a $\pm 0.5 \%$ shell really exists.

Since the method of excess fractions is so accurate, it is possible to nondestructively determine the gas fill of the capsules to within about $\pm 3 \%$ if proper measurement of the index of refraction of the glass and equimolar DT versus density a re made. This is possible because each combination of wall thickness and gas fill is unique regardless of diameter.

\section{Mithod of Excess Fractions}

Table I defines the symbols used in the following riscussion. As shown by
Fig, 2, the height of a step can be measured under monochromatic light using light

Parallel monochromatic light
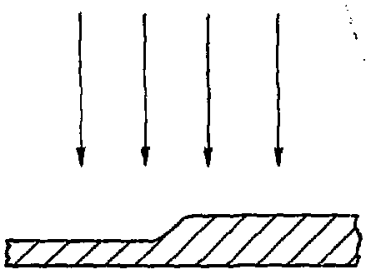

End view

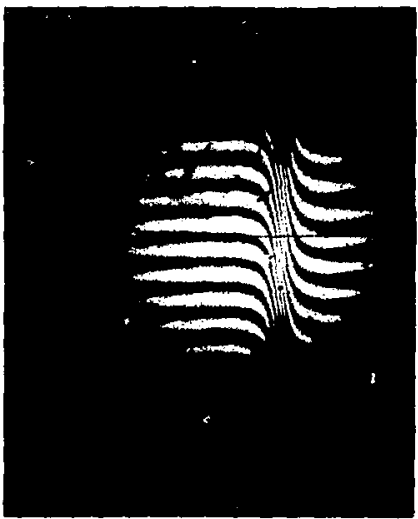

Fig. 2. Interference pattern for a slowly increasing step. The left shows a typical step profile, the right, an actual pattern obtained in a Twyman-green interferometer from such a step. 
Table 1. Ijist of symbols.

\begin{tabular}{ll}
\hline $\mathrm{i}$ & Integer specifying number of fringes \\
$\mathrm{f}$ & Fraction of fringe \\
$\lambda$ & Wavel ength of light, $\mu \mathrm{m}$, \\
$\mathrm{h}$ & Height of step, $\mu \mathrm{m}$ \\
$\mathrm{s}$ & Optical path length, $\mu \mathrm{m}$ \\
$\mathrm{S}$ & Dimensionalized optical path length, \\
$\left(\mathrm{s} / \mathrm{r}_{1}\right)$
\end{tabular}

interference by tracing a dark (minimum) or bright (maximum) path across the step. This gives the number of fringes $\mathbf{N}$, plus the fraction $f$. The thickness is, therefore, $(N+f) \frac{\lambda}{2}$, wher $2 \frac{\lambda}{2}$ is used because the light is reflected at the reference surface and traverses the height of the step twice. If the edge at the step approaches $90^{\circ}$, the ability to trace the path of a maximum or minimum is lost as shown by Fig. 3. It is possible to measure the fraction $f$, but not the number of fringes $N$. If the height is not too great, it is possible to use white light interference to determine $\mathrm{N}$. Also if it is possible to measure the step height by some other method accurate to some minimum ( $\mathrm{N}$ ?), the fraction can be measured and the absolute height then calculated. Another method, used to measure the step height when the reference is lost, is to use several wavelengths of light. The fraction $i$ is measured at each wavelength and the following can be written:

$$
\begin{aligned}
& \left(\mathrm{N}_{1}+\mathrm{f}_{1}\right) \frac{\lambda_{1}}{2}=\mathrm{h} \\
& \left(\mathrm{N}_{2}+\mathrm{f}_{2}\right) \frac{\lambda_{2}}{2}=\mathrm{h}
\end{aligned}
$$

or

$$
\begin{aligned}
\left(N_{1}+f_{1}\right) \lambda_{1}=\left(N_{2}+f_{2}\right) \lambda_{2} \& N_{1} & \\
= & I N T^{*}\left|N_{2} \frac{\lambda_{2}}{\lambda_{1}}\right| .
\end{aligned}
$$

FTake only the integer part of the real number.

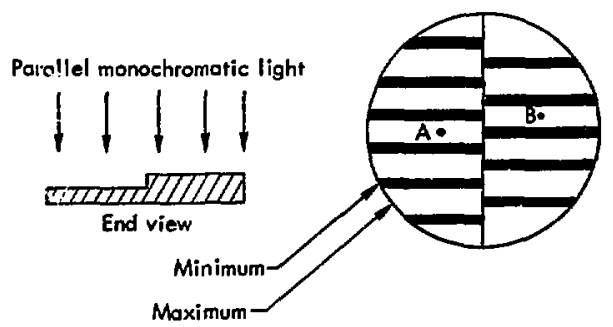

Fig. 3. Interference pattern with sharp step. The left shows a typical step profile, and the right, e schematic of the interference pattern. 
where $\lambda_{1}<\lambda_{2}$. Values are assumed for $\mathrm{N}_{2}$, and $\mathrm{N}_{1}$ is calculated. Then tigs. (1) and (2) are solved by an iterative process until their difference is a minimum.

In practice, three different wavelengths are used and the step height is approximately known. This increases the accuracy of the method by assuring the solution converges at the proper location. $F$ or purposes of this report, it is assumed that the fraction can be measured to $0.0 \mathrm{l}$, even though expcrimental data indicates an accuracy of 0.006 is easily obtained. Reference 6 indicates that measurement of the fraction to 0.1 is accomplished by eye and to 0.001 by photoelectric methods. Assuming a measurement to \pm 0.01 of the fraction and the use ci green light, we obtain an accuracy of about $\pm 0.0025 \mu \mathrm{m}$ or $0.25 \%$ for a $1-\mu \mathrm{m}$ step height.

\section{Average Wall Thickness Measurement}

For the shells in question, the ability to trace a dark or light interference band is lost due to the shape of the parts. It is not possible to use white light interference due to the limited coherence length of this source. For a step with exactly the same reflectance as the reference surface, it is possible to measure the fraction by determining the intensity of the light at a point on the step (B) opposite a point (A) on the reference as shown by Fig. 3. The intensity of the light reflecting $r$ ff tue step is compared with the intensity when the interference is at a maximum. One can tell if the light intensity is on the rising or falling part of the intensity curve by noting the position of the measurement relative to a maximum on the step. For the center of the glass shell, the absolute intensity of se light is impoisible to measure and compare with the backglound because of scattering, reflection, and absorption. It is therefore adyantageous to consider relative measurement, the technique discussed in this report. The interference pattern of the background surface is caused to "roll," i.e., go from a maximum to a minimum, etc., while the relative intensities of the background and center of the shell are measured. Figure 4 illustrates this situation. The background pattern appears to go from right to left. The frequency of the light intensity versus time of the center of the shell is exactly the same as that of the background surface interference pattern. Using light intensity plots of the background surface and that obtained at the center of the transparent shell, the phase or fraction can be determined. This is measured using three different wavelengths. The approximate thickness of the middle of the shell is obtained by using the interference pattern as descrioed by Ref. 2 . Knowing the fractions of the three wavelengths, it is possible to solve for $\mathrm{N}_{1}$, $N_{2}$, and $N_{3}$. This allows a path length difference between the center of the shell and a ray from the reference mirror, $M 1$, to be determined. As shown by Fig. 5, and neglecting refraction, this difference is:

$$
\begin{aligned}
\Delta s_{0}=s_{0}-s_{\operatorname{Ref}} & =4\left(r_{1}-r_{2}\right) \\
& \times n^{+}+4 r_{2} n^{\prime \prime}-4 r_{1} n
\end{aligned}
$$


$(n+i) \lambda \cdot \Delta s_{0}$ and $r_{1}-r_{2}=\ell$.

Divale by $r_{1}$ to dimensionlize:
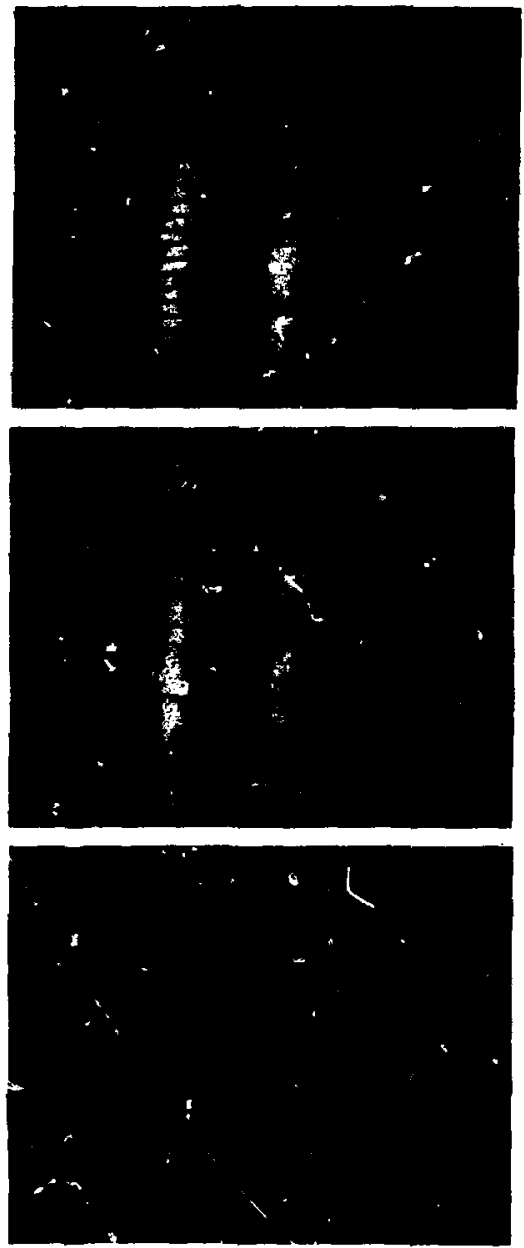

Fig. 4. Background and shell interference appearance as pattern is calised to roll. Fracticin if center of shell is about 0.7 .
$(\mathrm{N}+\mathrm{f}) \frac{\lambda}{\mathrm{r}_{1}}=\Delta \mathrm{s}_{0}$

$$
=4\left[L n^{\prime}+(1-L) n^{\prime \prime}-n\right]
$$

or

$$
L=\frac{(N+E) \frac{\lambda}{4 \Gamma_{1}}-\left(n^{\prime \prime}-n\right)}{n^{\top}-n^{\prime \prime}} .
$$

If $n=n^{\prime \prime}=1.00$

$$
L=\frac{(N+e) \frac{\lambda}{4 r_{1}}}{n^{1}-1} \text {. }
$$

An estimate of the accuracy of the average wall thickness can be arrived at as follows:

$$
\mathrm{L}=\mathrm{g}\left(\mathrm{f}, \lambda, \mathrm{n}^{\prime}\right)
$$

$$
\begin{aligned}
\frac{d L}{L}=\left[\frac{\partial L}{\partial f} d f+\frac{\partial L}{\partial \lambda} d \lambda\right. & \left.+\frac{\partial L}{\partial n^{1}} d n^{\prime}\right] / \\
& {\left[\frac{(N+f) \frac{\lambda}{4 r_{1}}}{n^{1}-1}\right] . }
\end{aligned}
$$

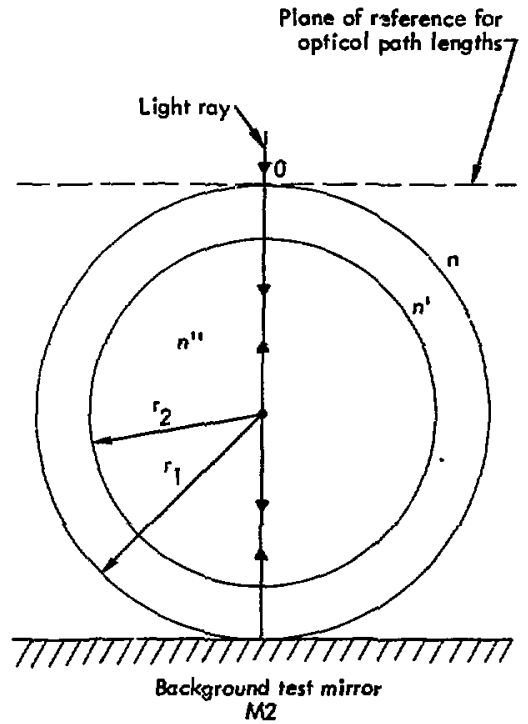

Fig. 5. Schematic of transparent shell with light ray through the center. 
$\frac{d L}{L}=\frac{d f}{(N+f)}+\frac{d \lambda}{\lambda}+\frac{d n^{\prime}}{n^{\prime}-1}$.

As an example, assume:

$$
\begin{aligned}
r_{1} & =20 \mu \mathrm{m} \\
\ell & =1.0 \mu \mathrm{m}, \quad L=0.05 \\
n^{\prime} & =1.5 \\
d f & =0.01 \\
d \lambda & \sim 10^{-5} \mu \mathrm{m} \\
\lambda & \sim 0.5 \mu \mathrm{m} \\
\mathrm{dn} n^{\prime} & =0.001 \\
\mathrm{~N}+f & =4.00
\end{aligned}
$$

or

$$
\frac{d L}{L} \sim 0.005, \text { i.e., } 0.5 \%
$$

Since this error comes primarily from the error in the fraction and index of refraction measurements, it is felt that this estimate of maximum error is very conservative. The error in these two measurements can be easily drcreased by a factor of two.

\section{Shell Wall Uniformity}

The determination of shell wall uniformity involves measuring optical path lengths at the shell center and away from the center or making two measurements equidistant from the center. Referring to Fig. 6, the optical path length of an

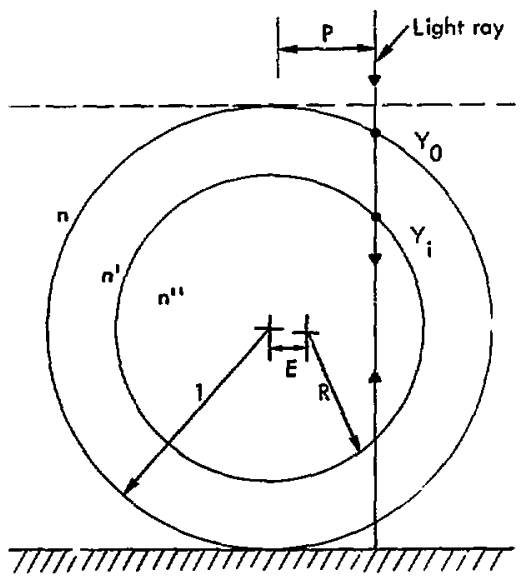

Test ar background mirrar

Fig. 6. Schematic of transparent shell with nonuniform "ralls. arbitrary incoming ray can be written for a normalized transparent shell.

$$
\begin{aligned}
S_{P}=4\left[\left(1-Y_{0}\right)\right. & n \\
& \left.+\left(Y_{0}-Y_{i}\right) n^{\prime} \cdots Y_{i} n^{\prime \prime}\right] .
\end{aligned}
$$

Let $n=n^{\prime \prime}=1.00$,

$$
S_{P}=4\left[1+\left(n^{i}-1\right)\left(Y_{0}-Y_{i}\right)\right] .
$$

At the center, $\mathrm{P}=0, \mathrm{Y}_{0}=1$,

$$
S_{0}=4\left[1+\left(n^{\prime}-1\right)\left(1-Y_{i}\right)\right] \text {. }
$$

If the shell were perfect,

$$
Y_{i}=R \text { at } P=0 .
$$

Assuming a perfect shell, the optical path length at $P$ can be calculated and compared to that actually measured. For an offset inner surface,

$$
\begin{aligned}
S_{P}=4\left\{1+\left(n^{\prime}-1\right)\right. & {\left[\left(1-P^{2}\right)^{1 / 2}\right.} \\
& \left.\left.-\left[R^{2}-(P-E)^{2}\right]^{1 / 2}\right]\right\} .
\end{aligned}
$$

and for pert . shell, 


$$
\begin{aligned}
S_{P^{\prime}}=4\left(1+\left(n^{\prime}-1\right)\right. & {\left[\left(1-P^{2}\right)^{1 / 2}\right.} \\
& \left.\left.-\left(R^{2}-P^{2}\right)^{1 / 2}\right]\right\} .
\end{aligned}
$$

To estimate the accuracy of such a measurement, assume the followi 3 :

$$
\begin{aligned}
r_{1} & =20 \mu \mathrm{m} \\
\ell & =1.0 \mu \mathrm{m}, \\
R & =0.95 \\
P & =0.51 \\
n^{\prime} & =1.5,
\end{aligned}
$$

then

$S_{P}^{\prime}=4.1174$ or $S_{P}^{\prime}=82.3470$

$(\mathrm{N}+\mathrm{f})_{\mathrm{F}}^{\dagger}=4.3866 \sim 4.39$.

Let $(N+f)_{P}=4.40$; i.e., $\Delta f=0.01$,

$$
S_{P}=4.1177
$$

Solving for $\mathrm{E}$ :

$$
\mathrm{E}=0.00028 \text { or } \mathrm{e}-0.0056 \mu \mathrm{m} \text {. }
$$

It is possible to easily detect an offset of $\sim 0.006 \mu \mathrm{m}$. A more accurate method would be to measure the fraction $-P$ relative to $+P$. Since the offset increases the optical path length at $+P$ and decreases it at $-P$, a smaller offset can be measured. For example:

Let

$$
\begin{aligned}
P & = \pm 0.51 \\
R & =0.95 \\
\Delta \mathbf{r} & =0.01 \\
\mathbf{r}_{1} & =20 \mu \mathrm{m} \\
\mathbf{n}^{\prime} & =1.5
\end{aligned}
$$

$$
\begin{aligned}
\Delta S p=S \bar{p}-S p^{+} & =2\left[\left[R^{2}-(P-E)^{2}\right]^{1 / 2}\right. \\
& \left.-\left[R^{2}-(-P-E)^{2}\right]^{1 / 2}\right] .
\end{aligned}
$$

For the example given, $\Delta S p=1.338$ $\times 10^{-4}$.

Solving for $\mathbf{E}$ :

$$
\mathbf{E} \sim 0.00011 \text { or } \mathrm{e} \sim 0.0022 \mu \mathrm{m} \text {. }
$$

The wail uniformity can be specified to be better than $0.22 \%$.

\section{Equipment}

The following equipment is required to utilize the described method:

- A moving reference surface M1 to cause the interference pattern to "roll" on the background surface M2.

- A high-quality interference microscope.

- Pic iup probes for the background surface and light intensity variations at the center of thc shell.

- Amplification circuitry for the light pickups.

- Some means of recording light intensity versus time for all pickups or an interface to some machine capability.

A schematic of a system is shown by Fig. 7. The microscope used is a highquality Zeiss" with a Twyman-Green twoarm interference system. It has matched objectives in the two arms and these are normally focussed onto two reflecting surfaces. In Fig. 7, these surfaces are

\footnotetext{
${ }^{\text {F }}$ Reference to a company or product name does not imply approval or reconimendation of the product by $t^{\prime} \approx$ University of California or the U.S. Ene.gy Research \& Development Administration to the exclusion of others that may be suitable.
} 
designated $\mathrm{M} 1$, reference mirror, and M2, test or background mirror. Total magnifications of $100 \mathrm{X}, 250 \mathrm{X}$, and $600 \mathrm{X}$ are normally available for visual work with image plane magnifications of $10 X$, $25 X$, and $60 X$ available. At LLL, $M 1$ is normally a reflecting stage micrometer and objective 1 is focussed onto its surface. This provides calibration marks for all work. M2 is then moved to the focis of objective 2 by means of a small $X, Y$, ano $Z$ stage mounted on the micros cope.

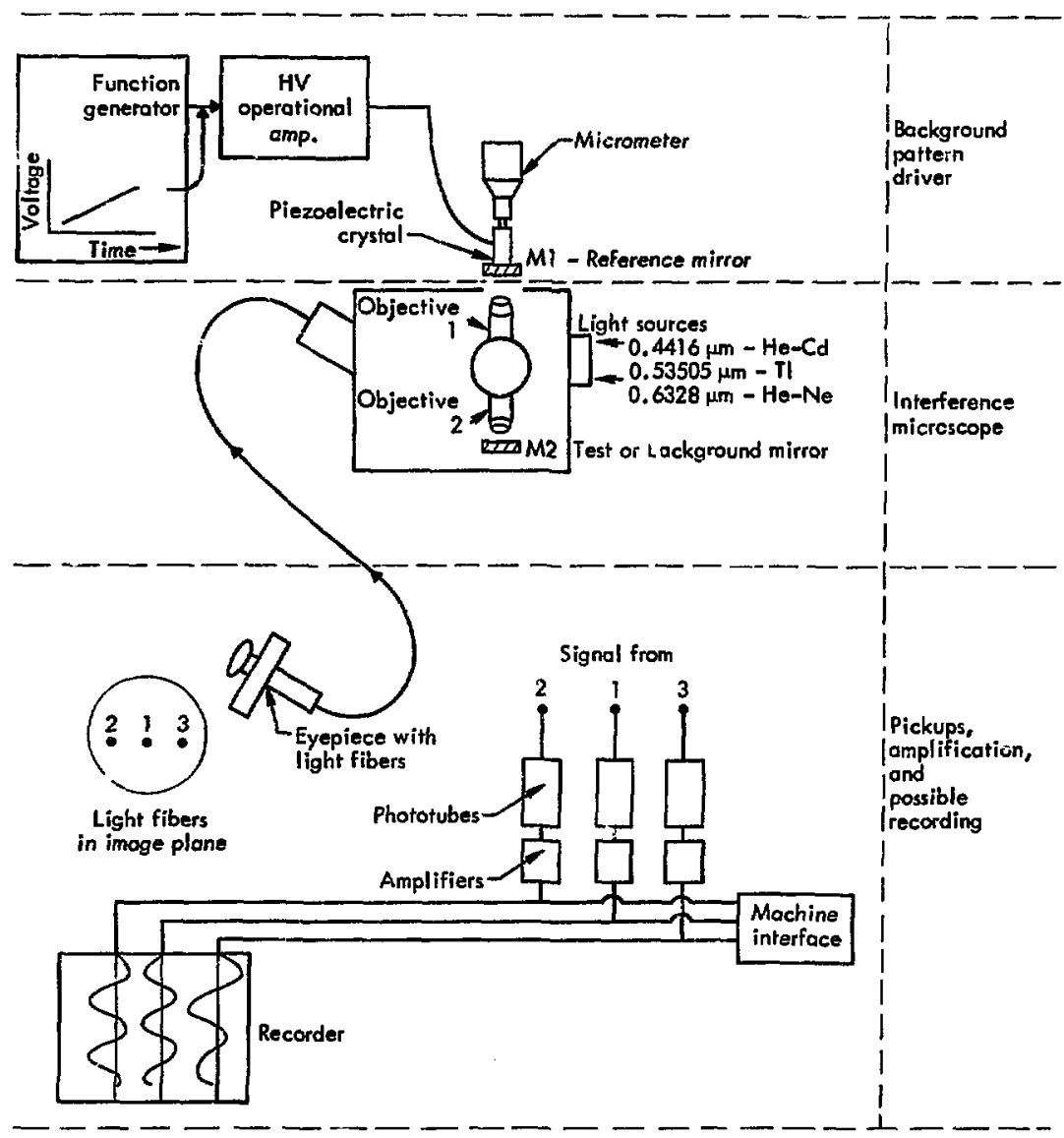

Fig. 7. Schematic of systern necessary to measure excess fractions under an interference microscope. 
The pattern driver will cause $M 1$ to move up or down at a rate controlled by the function generator and $\mathrm{HV}$ operational amplifier. The driver transducer is a piezoelectric-crystal micrometer assembly with movements of $5.5 \mu \mathrm{m} / 1000 \mathrm{~V}$ or $15 \mu \mathrm{m} / 1000 \mathrm{~V}$. A ramp signal is input to the amplifier and causes $M 1$ to be driven at a constant rate. For each $\frac{\lambda}{2}$ of movement in either direction, the background pattern will shift a full fringe. For a given point, the intensity of light versus time wi l be sinusoidal.

Three different wavelengths are required for the system. The microscope has a $535.05-\mathrm{nm}$ thallium light available. A 632.8-nm He-Ne and a 441.6-nm He-cd provide the other two wavelengths. Two movable mirrors are required to provide wavelength selection. Since the laser light is extremely coherent, interference will occur at each reflection within the microscope optics, and thus it is necessary to decrease the light's coherence before it enters the microscope. A nethod suggested by J. Bryan can be used which is to shine the light on a thin, spinning, frosted wheel. This wheel will be located at the focal point of the microscope condensing lens.

The light pickups are three $50-\mu \mathrm{m}$ glass fibers located in the image plane of the microscope. The arrangement of the fibers is shown in Fig. ?. The two outside fibers, 2 and 3 , are used to insure the interference pattern is oriented properly with respect to the two actual measuring fibers, 2 and 1 . When the background pattern is in the correct orientation and moving past the fibers, the output of 2 and 3 will peak at exactly the same time. The center of the shell to be measured is placed under fiber 1 . As the pattern driver causes the background to roll, the signals from 1 and 2 are recorded and their phase difference can be determined.

The signals from the fibers are condusted to three separate photo tubes. Amplifjcation and some signal processing is accomplished by the photo tube, amplifier arrangement. The output available from the amplifiers can be either analogue or $\mathrm{BCD}$. Light fiber 1 can be movable in the image plane. The use of such carability will be discussed later.

The recording or measuring system in the simplest form is a three channel recorder. By recording signals 2 and 3 , it isn't necessary to exactly orient the background, as a line can be drawn between the peak of the two signais and the actual background reference signal at the shell center can be determined. By measuring the time of the occurrence of the background peaks and the peak of the signal from 1, the phase between the two signals can be determined. This type of measuring scheme is very desirable as one is not concerned with the absolute light intensity values, but only the occurrence of peaks or where the signal crosses the axis. The frequency of the signai from channels 1,2 , and 3 will always be exactly the same.

It is possible to automatically process the signal out of the amplifiers in several ways. One would be to use an electronic counter that turns on at the peak of signal 2 and off at the peak of signal 1. Another counter would count between the successive peaks of signal 2. By dividing the first count by the second, the excess 
fraction can be determined. In practice the average of about 10 cycles would be measured. By interfacing with a computer, total signal processing and subsequent calculations became available. This type of capability may be required in determining gas fill which will be discussed later.

\section{Production Usage}

In practice, the operator would adjust the background pattern until broad interference bands are visible. The center of the transparent shell to be measured is positioned under fiber 1. A wavelength is selected and the pattern driver is turned on. As the bands pass, fibers 2 and 3 are adjusted so that their signals peak simultaneously. Now the signals from all three filers can be recorded. Another wavelength is selscted and the process is repeated.

After the excess fractions have been determined for the three wavelengths, one can specify the range of $\mathrm{N}$ values since the approximate wall thickness is

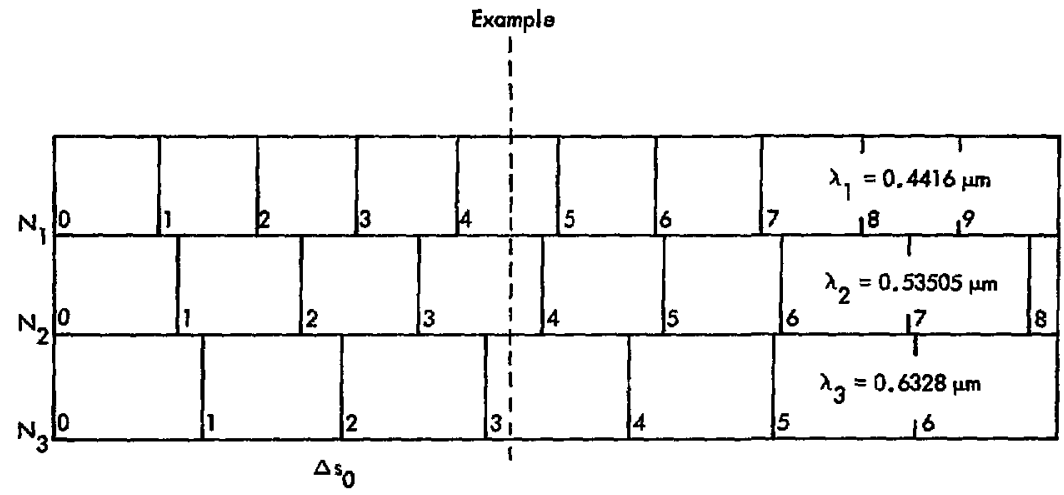

$$
\text { Example: Let } \begin{aligned}
& r_{1}=20 \mu \mathrm{m}, \begin{array}{l}
f=1.0 \mu \mathrm{m}_{r} n^{\prime}=1.500 \\
\pm 0.2 \mu \mathrm{m}
\end{array} \\
& f_{1}=0.52 \\
& f_{2}=0.73 \\
& f_{3}=0.15 \\
& 3 \leq N_{1}=5 \\
& \text { From seale } N_{1}=4, N_{2}=3, N_{3}=3 \\
& \text { Thus, } 1=0.9980
\end{aligned}
$$

Fig. 8. Scale to be us ed to det ermine $\mathrm{N}_{\mathrm{i}}$ for wavelengths of $0.4416,0.53505$, and $0.6328 \mu \mathrm{m}$. 
known. The simplest method of determining $N_{1}, N_{2}$, and $N_{3}$ is to use a scale as shown in Fig. 8. Once any $\mathrm{N}_{i}$ is determined, the actual path length is known. This can then be converted to average wall thickness using Eq. (8). Since light fiber 1 can be moved to any point ca the shell, it can be rnoved to say a planar radius of one-half the radius on both sides of the shell center and the path lengths of these two points compared. If they are not equal, the walls are not uniform. By rolling the ball, a higher overall accuracy on the ball specif ication can be made.

\section{Gas Fill Determination}

Determination of the DT fill is an important part of characterizing the target capsule. Researchers at KMSF measure the gas fill by breaking a statistical sample of shells after filling. The total gas pressure is determined by rupturing a shell in glycerol and measuring the diameter of the bubble formed. The quantity of tritium is determined by measuring total radioactivity of the gas from a broken shell in an ionization chamber and DT ratios are provided by a mass spectrometer. ${ }^{7}$ A nondestructive check of the existence of gas fill is accomplished prior to target firing by freezing the gas and optically measuring the frozen DT. Target fabricators at LASL have reported three methods of determining gas fill, One uses a $2.754-\mathrm{MeV}$ gamma ray source $\left({ }^{24} \mathrm{NA}\right)$ and the resulting $0.26-\mathrm{MeV}$ neutrons from the deuterium atom are counted $\left[{ }^{24} \mathrm{Na}\right.$, $D(\gamma, n)]$. The accuracy of such a scheme is reported to be $\pm 5 \% .^{8}$ Another : i que used is to bombard the filled capsuies with a $16.2-\mathrm{MeV}$ proton beam from a Van de Graaff accelerator and measure the resulting deuterons and tritons. An accuracy of $\pm 10 \%$ is reported using this technique. ${ }^{9}$ LASL and LLL both use the measurement of $x$ rays emitted from the shell walls as a result of tritium beta bombardment. ${ }^{10,11}$ A gas proportional counter is used at both labs with an accuracy of about $\pm 10 \%$ for the fills of interest. 3,12

This report discusses using the method of exact fractions to measure gas fill. For the technique to be successful, it is necessary to measure the index of refraction versus density for the gas mixtures of interest.

Referring to Fig. 9 and neglecting the effects of refraction at the interfaces, $w \in$ can write:

$$
\begin{aligned}
S_{\mathrm{P}}=4\{n[1 & \left.-\left(1-\mathrm{P}^{2}\right)^{1 / 2}\right] \\
& +n^{\prime}\left[\left(1-\mathrm{P}^{2}\right)^{1 / 2}\right. \\
& \left.-\left[(1-\mathrm{L})^{2}-\mathrm{P}^{2}\right]^{1 / 2}\right] \\
& \left.+n^{\prime \prime}\left[(1-\mathrm{L})^{2}-\mathrm{P}^{2}\right]^{1 / 2}\right\} .
\end{aligned}
$$

This is the "simple theory" described by Ref. 2. For $P=0$ (center of shell), this reduces to:

$$
S_{0}=4\left[L n^{\prime}+(1-L) n^{\prime \prime}\right] \text {. }
$$

Rearranging:

$$
L=\left(\frac{S_{0}}{4}-n^{\prime \prime}\right) /\left(n^{\prime}-n^{\prime \prime}\right)
$$


or

$$
\mathbf{n}^{\prime \prime}=\left(\frac{S_{0}}{4}-\operatorname{Ln}\right) /(1-L) .
$$

It is know $n$ that for gas, $n^{\prime \prime}=f(\rho)$. It is therefore, necessary to measure the index of refraction of equimolar DT versus density. This has been accomplished for normal hydrogen with results shown by Fig. 10. ${ }^{13}$ This data will be used later to illustrate the powerfulness of the proposed system.

The simplest way to determine the gas fill is to measure the optical path length at the shell center prior to filling. The value of $L$ is calculated from $E q$. (8). After filling, the optical path length is again measured at the center of the shell. The increase in this path length will be due to the increase of $n^{\prime \prime}$, the index of refraction of the inner filled space. Knowing $L$ and $\mathbf{S}_{0}, n^{\prime \prime}$ can be determined by Eq. (20). The density of the gas can

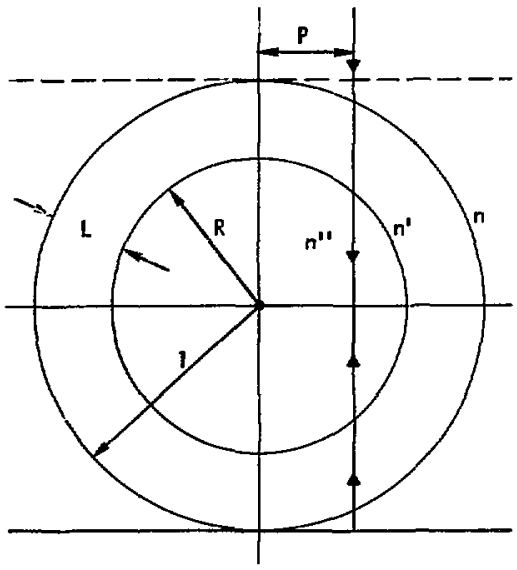

Test or background mirror

Fig. 9. Schematic of transparent shell with arbitrary incoming light ray and neglecting refractive effects.

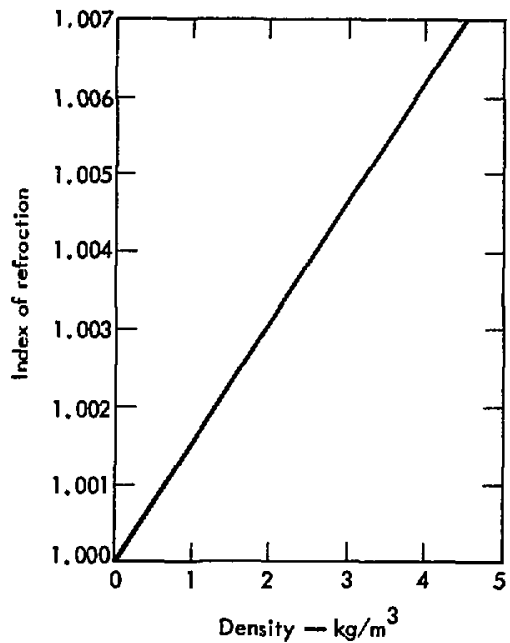

Fig. 10. Refractive index versus density for normal hydrogen at $298.15 \mathrm{~K}^{13}$

then be read off of a chart or calculated using an equition which relates density to index of refraction. This method takes advantage of the fact that all measurments are taken at the shell center, therefore, refraction is not considered.

Due to handling considerations, it is desirable to perform all measurements on the shell after filling. This decreases the number of shells to be individually handled and requires only one setup under the microscope. For a previously filled shell, there are an infinite combination of

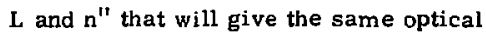
path length at the center of the shell. There are certain restrictions on the relative values of $L$ and $n "$. These are:

$$
\mathrm{n}^{\prime \prime}>\frac{\mathrm{S}_{0}}{4} \text {. }
$$

If

$$
n^{\prime \prime}=\frac{s_{0}}{4^{2}}
$$




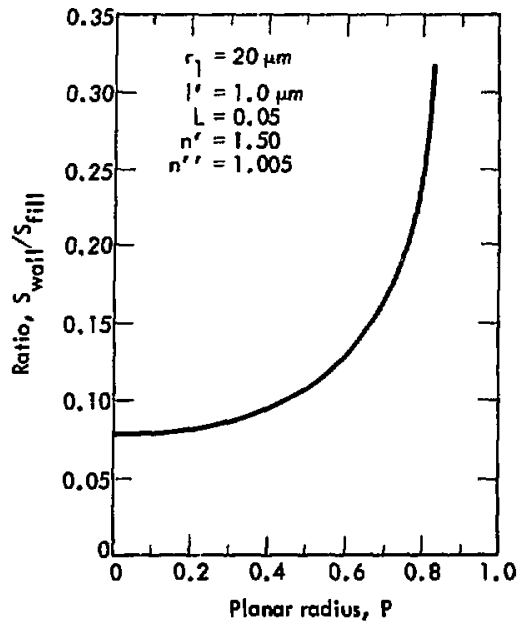

Fig. 11. Ratio of wall-to-gas fill optical path length contribution versus planar radius. then

$$
\mathrm{L}=0 \text {, i.e., no wall. }
$$

And

$$
L \leq \frac{s_{0}}{\frac{4}{n^{\prime}}-1} \text { since } n^{\prime \prime} \geq 1.00 \text {. }
$$

It is instructive to consider the contribution to path langth of the shell walls relative to the gas fill. Figure 11 shows such a comparison for:

$$
R=\frac{S_{\text {wall }}}{S_{\text {fill }}}
$$

Note that as $P$ increases, the contribution to the totai path length by the wall changes. This change in relative contribution is unique for any combination of $L, n^{\prime \prime}$, and ouside diameter. It is this fact that allows the gas fill to be determined. Table 2 lists additional comparisons and

Table 2. Ratio of wall contribution to inner fill contribution: ratio $=\mathrm{s}_{\mathrm{wall}} / \mathrm{s}_{\mathrm{fill}}$.

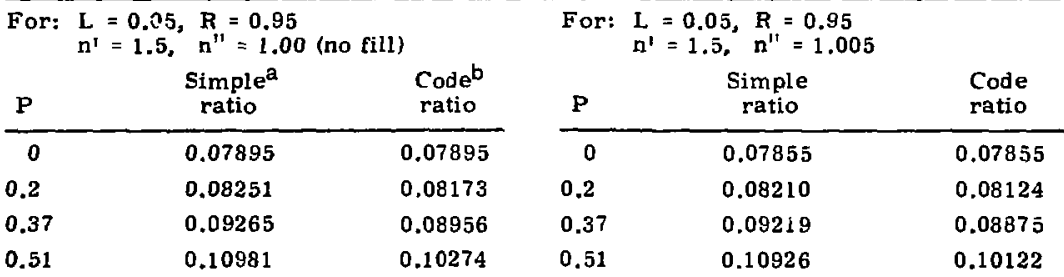

For: $L=0.05, R=0.95$ $n^{\prime}=1.5, n^{\prime \prime}=1.0051$

\begin{tabular}{ccc}
$P$ & $\begin{array}{c}\text { Simple } \\
\text { ratio }\end{array}$ & $\begin{array}{c}\text { Code } \\
\text { ratio }\end{array}$ \\
\hline 0 & 0.07855 & 0.07855 \\
0.2 & 0.08209 & 0.08123 \\
0.37 & 0.09218 & 0.08874 \\
0.51 & 0.10925 & 0.10119
\end{tabular}

For: $L=0.055, \quad R=0.945$

$$
n^{\prime}=1.5, \quad n^{\prime \prime}=1.005
$$

\begin{tabular}{ccc}
$F$ & $\begin{array}{c}\text { Simple } \\
\text { ratio }\end{array}$ & $\begin{array}{c}\text { Code } \\
\text { ratio }\end{array}$ \\
\hline 0 & 0.05687 & 0.08687 \\
0.2 & 0.09082 & 0.08989 \\
0.37 & 0.10209 & 0.09838 \\
0.51 & 0.12121 & 0.11259
\end{tabular}

\footnotetext{
${ }^{a}$ Neglect effect of refraction.

${ }^{b}$ Ray trace code results.
} 

Table 3. Example fraction measurements at $\mathbf{P}=0.51$ and constant $\mathrm{S}_{0}$ and outside diam-
eter.

\begin{tabular}{cllcccc}
\hline Shell & \multicolumn{1}{c}{$\mathrm{L}$} & $\mathrm{n}^{\prime \prime}$ & \multicolumn{1}{c}{$\mathrm{S}_{0}$} & $\left(\mathrm{~N}+\mathrm{f}_{0}\right.$ & $\mathrm{S}_{0.51}$ & $(\mathrm{~N}+\mathrm{f})_{0.51}$ \\
\hline 1 & 0.05 & 1.005 & 4.1190 & 4.44818 & 4.133382 & 4.9858 \\
2 & 0.0503 & 1.00484 & 4.1190 & 4.44818 & 4.133585 & 4.9933 \\
3 & 0.0496 & 1.00521 & 4.1190 & 4.44818 & 4.133111 & 4.9757 \\
\hline
\end{tabular}

shows results of a ray trace code that includes refraction.

If the capsule is filled and $S_{0}$ at the. shell is determined, one does not know the average wall thickness since $n "$ is not known. Given $S_{0}$ one can then measure $s_{p}$ at a $P$ of, say 0.51 , and another path length is determined. There is only one combination of $L$ and $n$ " that will give the two measured path lengths; therefore, both values are now known. Knowing n" allows determination of the gas fill if $n^{\prime \prime}$ versus density has been previously measured.

An illustration of certain combinations of outside diameter, wall thickness, and fill will make the method clearer. It will be assumed that the fill is hydrogen since index of refraction data is available as shown by Fig. 10. The equation for the straight line relationship is:

$$
n^{\prime \prime}=1.000+1.55347 \times 10^{-3} \rho,
$$

where

$$
\rho \text { is in } \mathrm{kg} / \mathrm{m}^{3} \text {. }
$$

It is further assumed that the excess fraction can be determined to $1 / 100$. This is conservative. Green light with a wavelength of $535.05 \mathrm{~nm}$ is used for the examples.

Given a measurement of $S_{0}$, there are three variables to consider: the outside diameter, the wall thickness, and the index of refraction (gas fill). First consider three shells $(1,2$, and 3$)$ with equal outside diameters. If $n_{1}^{\prime \prime} \neq n_{2}^{\prime \prime} \neq n_{3}^{\prime \prime}$ and $\mathrm{S}_{01}=\mathrm{S}_{02}=\mathrm{S}_{03}$, then $\mathrm{L}_{1} \neq \mathrm{L}_{2} \neq \mathrm{L}_{3}$. For example:

$$
\begin{array}{cl}
S_{0}=4.1190 & \begin{array}{l}
\text { (Nominal } 40-\mu \mathrm{m} \\
\text { o.d. with } l=1.0
\end{array} \\
(\mathrm{~N}+\mathrm{f})_{0}=4.44818 . & \begin{array}{l}
\mu \mathrm{m} \text { and } \mathrm{n}^{\prime \prime} \\
=1.005 \mu \mathrm{m})
\end{array}
\end{array}
$$

Results are given in Table 3 .

Note that for a change in $L$ and the corresponding change in $n^{\prime \prime}$, the fraction measured at $P=0.51$ is different. Each change in $L$ of about \pm 0.0004 causes about a \pm 0.01 fraction change at $\mathbf{P}=0.51$. Now this corresponds to an $n^{\prime \prime}$ change of about \pm 0.0002 . A change in $n^{\prime \prime}$ of \pm 0.0002 equals a change in density of about $\pm 0.1 \mathrm{~kg} / \mathrm{m}^{3}$. For the fill assumed $\left(\sim 3.3 \mathrm{~kg} / \mathrm{m}^{3}\right)$, this is about $\pm 3 \%$.

The other possibility for a known $\mathrm{S}_{0}$ is a change in the outside diameter of the shell. Again assume:

$S_{0}=4.1190$ and an outsiae diameter $=41 \mu \mathrm{m}$.

Results are given in Table 4.

Table 4. Example fraction measurements at $\mathbf{P}=0.51$ and a constant $S_{0}$. but a different outside diameter.

\begin{tabular}{lcccc}
\hline$L$ & $n^{\prime \prime}$ & $s_{0}$ & $(N+f)_{0}$ & $(N+f)_{0.51}$ \\
\hline 0.05 & 1.00424 & 4.1190 & 4.1161 & 5.0166 \\
0.0496 & 1.00521 & 4.1100 & 1.1161 & 5.1003 \\
\hline
\end{tabular}


Again $(\mathrm{N}+\mathrm{f})_{0.51}$ is different for each $L$ and $n$ " combination and also different from the shell with a $40-\mu \mathrm{m} 0, \mathrm{~d}$. In practice, the outside diameter can be measured easily to \pm 0.5 to $0.7 \mu \mathrm{m}$ on a production basis and to $\pm 0.1 \mu \mathrm{m}$ using a TEM (transmission electron microscope).

\section{Conclusions}

The system describeri allows use of the method of excess fractions with a highquality interference microscope. This provides the capability to measure the average wall thickness of laser fusion transparent shells to better than $0.5 \%$ and wall uniformity to better than $0.3 \%$. Although only details for characterizing laser targets have been covered, the system would be useful for many types of measurements where high magnifications are required.

\section{Acknowledgments}

The author would like to thank the following for their valuable suggestions and assistance: C. Hendricks of $Y$ Division, J. Bryan and J. Sonderman of Material Fabrication Division, C. Souers of Chemistry, and T. Ramos of Nuclear
Explosives Engineering Division. Rita Treat of Nuclear Explosives Engineering Division must be complimented on her abilities to decipher the author's initial writings. This work was performed in support of Y Program, laser fusion activities. 


\section{References}

1. D. W. Gregg, The Measurement of Wall Thickness and Uniformity of Glass Microballoons, Lawrence Livermore Laboratory, Rept. UCRL -51500 (1973).

2. R. R. Stone, D. W. Gregg, and P. C. Souers Nondestructive Inspection of Transparent Microtargets for Laser Fusion, Law rence Livermore Laboratory, Rept. UCRL -76113 (1974).

3. J. Fries, Los Alamos Scientific Laboratory, Los Alamos, N. M., private communication (March 26, 1975).

4. D. Solomon, KMSF, Ann A rbor, Mich., private commulication (Feb. 21, 1975).

5. E. H. Farnum and R. J. Fries, Fabrication of Advanced Laser Fusion Targets, Los Alamos Scientific Laboratory, Los Alamos, N. M., Rept. LS-UR 74-1517 (1974).

6. J. Dyson, lrterferometry as a Measuring Tool (The Machinery Publishing Co., Ltd., London, 1970$)$ p. 113.

7. G. Charatis, J. Downward, R. Goforth, B. Guscott, T. Henderson, S. Heldum, R. Johnson, K. Moncur, T. Leonard, F. Mayer, S. Segall, L. Siebert, D. Solomen, and C. Thomas, Experimental Study of Laser Driven Compression of Spherical Glass Shells. Presented at the Fifth Conference on Plasma Physics and Controlled Nuclear Fusion Research, Tokyo, Japan (1974).

8. J. T. Caldwell, H. F. Atwater, E. H. Farnum, R. J. Fries, and A. K. Hyder, Nondestructive Fuel Assay of Laser Targets II. Photonuclear D $(\gamma, n)$ Method.

Los Alamos Scientific Laboratories, Los Alamos, N. M., Rept. LA-UR 74-1496 (1974).

9. N. Jarmie, P. Lovoi, E. H. Farnum, R. J. Fries, and F. Young, Nondestructive Fuel Assay of Laser Targets III. Elastic Scattering Method, Los Alamos Scientific Laboratories, Los Alamos, N. M., Rept. LA-UR 74-1518 (1974).

10. P. C. Souers, R. T. Tsugawa, and R. R. Stone, Fabrication of the Glass Microballoon Laser Target, Lawrence Livermore Laboratory, Rept. UCRL-51609 (1974).

11. R. J. Fries and E. H. Farnum, Nondestructive Fuel Assay of Laser Targets 1. X-Ray Method, Los Alamos Scientific Laboratory, Los Alamos, N. M., Rept. LA-UR 74-1458 (1974).

12. P. C. Souers, Lawrence Livermore Laboratory, private communication (April 1, 1975).

13. D. E. Diller, J. Chem. Physics 49,7 (1968).

MBB/le/lmc 